First Peoples Child \& Family Review

An Interdisciplinary Journal Honouring the Voices, Perspectives, and Knowledges of First Peoples through Research, Critical Analyses, Stories, Standpoints and Media Reviews

\title{
In Consideration of the Needs of Caregivers: Grandparenting Experiences in Manitoba First Nation Communities
}

\section{Rachel Eni, Carol D.H. Harvey and Wanda Phillips-Beck}

Volume 4, Number 2, 2009

URI: https://id.erudit.org/iderudit/1069332ar

DOI: https://doi.org/10.7202/1069332ar

\section{See table of contents}

\section{Publisher(s)}

First Nations Child and Family Caring Society of Canada

\section{ISSN}

1708-489X (print)

2293-6610 (digital)

Explore this journal

Cite this article

Eni, R., Harvey, C. \& Phillips-Beck, W. (2009). In Consideration of the Needs of Caregivers: Grandparenting Experiences in Manitoba First Nation Communities. First Peoples Child \& Family Review, 4(2), 85-98. https://doi.org/10.7202/1069332ar
Article abstract

Grandparents are valued in traditional and contemporary Aboriginal societies. In this paper we summarize traditional knowledge from Manitoba Aboriginal experiences, and we provide data from contemporary on-reserve grandmothers. Data for this study were collected in 2007 in 16 First nations Manitoba communities. Open-ended semi-structured in-person interviews were conducted in maternal-child centers that provide programs for developmental health for children and their parents (prenatal to age 6). Of the 100 people interviewed, ten of those were grandmothers, and their stories are analyzed in this paper. Results showed that grandmothers provided cultural transmission to subsequent generations, ensured child safety, provided acceptance and care for grandchildren, were challenged by inadequate and unsafe housing and communities, had difficulty proving educational supports for grandchildren, were supported by a network of kin, found community support inconsistent, needed to make a living, and needed more health supports. Implications for policy and research are given at the end of the paper.
Copyright @ Rachel Eni, Carol D.H. Harvey, Wanda Phillips-Beck, 2009
This document is protected by copyright law. Use of the services of Érudit (including reproduction) is subject to its terms and conditions, which can be viewed online.

https://apropos.erudit.org/en/users/policy-on-use/ 


\title{
Tiust Peoples Child \& samily Review
}

An Interdisciplinary Journal Honoring the Voices, Perspectives and Knowledges of First

Peoples through Research, Critical Analyses, Stories, Standpoints and Media Reviews

\section{In Consideration of the Needs of Caregivers: Grandparenting Experiences in Manitoba First Nation Communities}

\author{
Rachel Enia , Carol D.H. Harvey ${ }^{b}$, and Wanda Phillips-Beck ${ }^{c}$
}

${ }^{a} \mathrm{PhD}$, Assistant Professor and Researcher in Canadian Aboriginal Health Research in the Department of Community Health

Sciences \& Family Social Services, \& Principal Researcher of the Maternal Child Health Strengthening Families Program, Winnipeg, Manitoba, Canada.

${ }^{\mathrm{b}} \mathrm{PhD}$, Professor and Senior Scholar, Department of Family Social Sciences, Winnipeg, Manitoba, Canada.

${ }^{c}$ RN, BN, Nurse Program Advisor for the Manitoba First Nation Maternal Child Health Strengthening Families Program, and Masters Student, Department of Community Health Sciences, Faculty of Medicine, University of Manitoba, Winnipeg, Manitoba, Canada.

Grandparents can provide valuable time for the bonding of love and understanding between the generations. However, grandparents with primary parenting responsibilities have multiple and unique challenges. They have to balance the care of their grandchildren with concern for the lack of parenting by their own offspring. Moreover, although central to community value systems and a personal sense of meaningfulness, they are assuming primary care for young children at developmental periods in their own lives where personal life goals and health matters may conflict and must, therefore, become negotiated, often at a cost to themselves. Grandparents living with grandchildren without the middle or parent generation present are referred to in the mainstream literature as "skipped generation" families. Research indicates these families are more likely to be economically impoverished (Wang \& Marcotte, 2007), headed by women (FullerThompson, 2005), and have household heads that are

Questions or correspondence concerning this article may be addressed to:

eni@cc.umanitoba.ca

charvey@cc.umanitoba.ca

\begin{abstract}
Grandparents are valued in traditional and contemporary Aboriginal societies. In this paper we summarize traditional knowledge from Manitoba Aboriginal experiences, and we provide data from contemporary on-reserve grandmothers. Data for this study were collected in 2007 in 16 First nations Manitoba communities. Open-ended semi-structured in-person interviews were conducted in maternal-child centers that provide programs for developmental health for children and their parents (prenatal to age 6). Of the 100 people interviewed, ten of those were grandmothers, and their stories are analyzed in this paper. Results showed that grandmothers provided cultural transmission to subsequent generations, ensured child safety, provided acceptance and care for granchildren, were challenged by inadequate and unsafe housing and communities, had difficulty providing educational supports for grandchildren, were supported by a network of kin, found community support inconsistent, needed to make a living, and needed more health supports. Implications for policy and research are given at the end of the paper.
\end{abstract}

unemployed (Fuller-Thompson, 2005). In Canada, grandparents-as primary-caregivers-to-their-grandchildren is a relationship status that is far more common among Aboriginal families, in general.

To better understand the health and social benefits (and costs) of this particular style of parenting, we discussed grandparenting with Aboriginal women in Manitoba. They were part of a larger research project of the Maternal Child Health Strengthening Families Program. The study explored the experiences of parenting and raising children in First Nations communities across Manitoba. We used a qualitative approach to interview 10 First Nations grandmothers living and raising families in their communities. In contrast to findings from previous research, we learned that grandparenting signified a very different connotation for our study participants. Indeed, even the concept of "skipped generation" needs to be 


\section{Acknowledgements:}

The authors would like to thank Gladys Rowe for assistance with preliminary data analysis, the participants for sharing their stories, and the funding agencies for making the data collection possible.

Funding for the data reported here came from: Assembly of Manitoba Chiefs and the University of Manitoba Aboriginal Capacity and Development Research Environments Program (ACADRE).

carefully considered: Does this concept apply within the First Nations people living on reserves? What does grandparenting mean in First Nation communities? What implications do these relationships mean in the dynamic functioning of First Nation families and communities in recent decades?

\section{Theoretical Perspectives}

Both ecological theory and a traditional Indigenous four-directions perspective guided this research. Ecological theory is appropriate because of its focus on human/environment fit. White and Klein (2002) identify ecological assumptions, including the dual nature of human biology and culture, human dependency on the environment and on each other, and the organization of human behaviour in time and space.

The philosophy of the four-directions perspective conveys the ways many Indigenous nations, such as Anishinaabe people (called Ojibway in English and Saulteaux in French) and Ininew (known as Cree in English) interpret the world. McDonnell (2006) cites Cajete (1999) for one interpretation of the four directions perspective, which suggests personal development, human relationships, interaction with the natural world, and traditional spirituality are incorporated into it. She calls it "a guide to living which can lead to self-discovery, selfmastery, personal fulfillment and good health" (p. 29). The four-directions perspective is based on a philosophy, which is similar to the ecosystem model, particularly in the role of the interdependent parts contributing to the whole (Lawrenchuk \& Harvey, 2001).

For the First Nations peoples of Manitoba, the four-directions perspective contains a vision for whole and healthy Indigenous communities in all areas of body, mind, heart and spirit. It also applies to environmental contexts, relationships and empowerment principles. It emphasizes strong extended family and clan-based relationships; interdependence among parts of the communities; interdependence with multiple levels of the environment, including land, natural resources, formal and informal health, education and social service supports; and responsibilities to govern self and to care for others in the communities (McDonnell, 2006).

The Medicine Wheel, as described to us by the traditional teachings of Mr. Wally Chartrand, a traditional teacher employed with Ma Mawi Wi Chi Itata's Windy Hill Community Learning and Wellness Centre at Hillside Beach in Manitoba, established the foundation for our research. Through his teachings to the researchers, programmers and participants of the Manitoba First Nation Maternal Child Health, Strengthening Families Program, a vision for healthy, supportive, well-balanced individuals and families living a holistic and balanced lifestyle was validated. In a traditional manner and setting, we learned the connections between our individual and collective lives and the pathological historical, political, social and economic circumstances that have and continue to surround us, and to perceive people as striving towards wellness in light of these hardships; which is a view that contradicts a medical perspective of the world where pathological behaviours are seen as emanating from within inherently dysfunctional selves. We learned to appreciate the depth of environmental impacts on individuals and their communities and to prepare programming and policy from such a vantage point.

The model, as presented by Mr. Chartrand, is a life course model that connects people to their environments and to historical circumstances. It explains our interconnections to others within the community and society and describes the unique contributions of men and women at different developmental stages throughout the life course. Within the model, neither sex is privileged beyond the other nor does any age or developmental period have quantitative advantage over the others. As individuals we are constant teachers and students. We provide and require love simultaneously - and the same is true regarding support, guidance and so on - such is the interdependent quality of people.

According to the Medicine Wheel philosophy, the life of an individual human being begins in-utero. At the time when a baby is taking form within the body its mother, others that will have an impact on the life circumstances of the baby are making preparations. Within this Aboriginal conception of the world, people are spiritual as much as physical. In-utero, the child begins to pick up ancestral messages and these messages have an impact on the health and meaning of his/her life. The life struggles of the parents and grandparents thus inscribe themselves upon the body of the developing fetus. As an illustration, consider the effects of a racist and unjust society on the emotions and behaviours of human beings. These impacts, 
manifested upon the bodies, minds and spirits of the older generations, materialize inside of the developing child, and ultimately become his/her/s to resolve. Mr. Chartrand illustrated this tendency of human development through stories regarding the intergenerational impacts of residential school and child welfare policies in Canada. It was also depicted through the search for love, intimacy and belongingness that seep through the life stories of residential school survivors to their grandchildren today.

According to this philosophy, ceremonies and rites of passage are fundamental to individual health and wellness. Through ceremony, individuals learn when and how they are connected to their communities of origin and to their ancestors. Life paths become illuminated and individuals can check when they are on-track or have deviated from the course. The rites of passage and intricate knowledge system are based upon interrelationships within the universe and respect for all life (Cook, 1985).

\section{Literature Review}

In preparation for this study, we conducted an academic review of the literature that included papers written of grandparenting relationships in different cultural contexts. In this review, we learned that most grandparents report high levels of satisfaction with the grandparenting role. Emotional ties across generations were investigated in a national U.S. sample by Monserud (2008). Sampling for this study utilized adult grandchildren, regardless of residency patterns, and results showed that "the parent-child relationship matters for grandparent-grandchild closeness" (p. 191). Differences in understandings of "grandparenting" were considerable between Aboriginal and mainstream populations. Within the Aboriginal climate, where extended family interconnection is the norm and tradition, grandparents assumed roles that were dissimilar from what is typical in the mainstream. Further, there were differences in terms of resources available to support grandparenting in First Nations and in historical circumstances that affected and continue to affect the relationship (i.e., of the Canadian colonial legacy).

\section{Focus on the "Skipped Generation" Families}

The notion of a "skipped generation" emanates from mainstream studies that focus on neglecting parents who leave the responsibilities of childcare giving to their parents. Parental neglect might be the result of emotional immaturity, unstable relationships between parental partners, or socio-economic difficulties that lead to a burden of childcare. According to Rothausen-Vange (2005), "skipped generation families are families in which grandparents raise children and parents are absent from the household. This is one area in which different subcultures may have different norms." After reading an article on Aboriginal family trends by Brant-Castellano (2002), it became apparent that to perceive a family situation as "skipped generation" implies an unchanging family situation. However, in her writing, we see the Aboriginal family context as being one surrounded within an atmosphere of acceptance, patience, and an allowance for healing within families. In her heartfelt description of the life of her brother Lloyd, Brant-Castellano writes:
By the time they were expecting their sixth child Lloyd's drinking was wildly out of control. He was arrested repeatedly for impaired driving and fighting. He was neglecting family support needs and his surliness was making life at home intolerable. His wife finally turned him out of their home and divorced him. It would take five years before he achieved sobriety and a degree of stability that would persuade his ex-wife to marry him again. In that interval his three oldest sons were growing to maturity. The network of two large extended families rallied to fill the vacuum created by Lloyd's lapse - uncles who stood as mentors and role models for the boys as they went through adolescence, grandparents who offered material aid and wisdom, sisters and in-laws who gave recognition and support to a mother determined to do whatever it took to provide for her children. After he resumed his place in the home Lloyd told his Alcoholics Anonymous group that he could never make up to his family for what he had put them through. Certainly there were emotional scars that remained after the reconciliation but his children weathered the storms exceedingly well, forming their own families and taking up their responsibilities as providers, pursuing trades and professions.

After reading this text, to insert the label "skipped generation" into an Aboriginal-based research would be to undermine the very essence of family in this context. Brant-Castellan's family never skipped over the healing needs and struggles of her brother, nor did his family ties fail to influence the generations that came after him. When he was able to do so, he returned to the family, and although, as she writes, some emotional scars remained after reconciliation, he was able to resume his role as husband to his wife and father to his children. The impacts of Canadian society over time cannot be undermined for their impacts on the life struggles of Lloyd, nor can we assume that the impacts of his struggles were not fully appreciated by those who loved and cared for him.

Across cultures, modern families can be very fluid, wherein grandparents assume greater or fewer parenting responsibilities. A U.S. study by Standing, Musil and Warner (2007) investigated transitions in grandparenthood, and results showed that grandmothers were 
committed to their grandchildren, but that changing roles engendered changes in personal freedom and brought with them mixed feelings about the evolving roles. Further, as Wang and Marcotte (2007) showed, in another American study, labor force participation by grandparents was higher if they had grandchild caring responsibilities. There was a gender difference as well, in that grandfathers worked more hours and grandmothers worked longer, as compared to other grandparents without child care activities.

Interpersonal relationships between the generations have also been studied. Goodman's (2007) study used triads among generations of skipped-generation households in the U.S. Grandchildren seemed to be able to compensate for parental neglect if grandmothers had close emotional bonds with them. Some households, however, had weak emotional ties across generations, and in those families, grandmothers had the lowest levels of well-being. What seemed to matter was not only the meaningfulness of the relationship to each of the individuals, but also the individual and community resources available to the grandparents to develop the relationship (for example, health and healthcare services, financial and other practical supports to the grandparents). Whether or not values such as respect for Elders and the central responsibility of extended families to share in childcare remained intact also affected individual health and family dynamics.

\section{Grandparenting in Canada}

Since the literature on grandparenting in First Nations was scant, we also looked at grandparenting in Canada as a whole. The research showed that $76 \%$ of all Canadians age 65 and older have grandchildren (Rosenthal \& Gladstone, 2007). Becoming a grandparent occurs in early mid-life, age 40-50, and thus grandparents often see their grandchildren into adulthood. Grandparents have an average of five grandchildren, and most do not live with them, although $4 \%$ live in multi-generational households (Milan \& Hamm, 2003). Contact with grandchildren is frequent (at least once a month), mediated by the parent generation (Rosenthal \& Gladstone, 2007). Canadian grandparents provide material and social support, in the form of money, services, and advice. To learn the grandparent role, people rely on memories of their own grandparents (King \& Elder, 1997). When people first become grandparents they are likely to be in the paid labor force; later on, there are more grandmothers than grandfathers due to the longer longevity of women (Rosenthal \& Gladstone, 2007).

Little appears to be known about ethnic differences in Canadian grandparenting (Rosenthal \& Gladstone, 2007), even though nearly $20 \%$ of Canadians are immigrants
(Statistics Canada, 2008). Current grandparenting practices and beliefs within Aboriginal populations (First Nations, Inuit, and Métis) have rarely been studied. Some statistical data does exist, however. In Manitoba where the overall Indigenous population is now 12\% (Statistics Canada, 2008), it is surprising that so little scientific work has been conducted on grandparents. One exception is McDonnell's (2006) qualitative study on the effects of diabetes on grandparenting among Manitoba Anishinaabe grandparents.

Another contribution to the scant literature on Aboriginal grandparents is the work of Fuller-Thomson on "skipped generational households" (2005, p. 331), in which grandparents and grandchildren are living together. She utilized Stats-Can information on family patterns to reach her conclusions. Although the statistics do provide us with some information on the prevalence of family forms, she could not have interpreted cultural meaning of the trends through the data. According to Fuller-Thompson, in this family form, the grandparent has the responsibility for raising the grandchildren, often accompanied with worry over offspring who are either unable or unwilling to parent. She reports this family form as being more common in Aboriginal families. Using Statistics Canada figures of 1996, she reported "First Nations Canadians were vastly over-represented [among skipped generation families] with more than $17 \%$ of care giving families were of First Nations descent, although First Nations persons comprise only $2.8 \%$ of the total population" (p. 332).

\section{Effects of Governmental Policies on Aboriginal Families}

Various Euro-Canadian practices and policies have dominated Aboriginal family interconnections, community ways of life and laws. For example, in the colonial period 1750-1900, the fur trade conducted by the English and French settlers changed Aboriginal cultures by upsetting residency patterns, kinship roles and relationships, as well as through the spread of European diseases (Castellano, 2002; Young, 1988 as cited in McDonnell, 2006). Over the course of this history, traditional migrations ceased and many died of starvation.

Colonial governments introduced legislation policies to "deal with" "Indians," and they established a residential reserve system which employed "Indian agents," powerful individuals from European decent whose job it was "to police, 'civilize,' Christianize, and educate the Aboriginal people" (McDonnell, 2006, p. 11) according to Eurocentric values.

Residential schools were established in 1894, forcing assimilation of Aboriginal children via destruction of traditional language and values (Ing, 1991 as cited by McDonnell, 2006; Lawrenchuk \& Harvey, 2001). 
Not only were children adversely affected, but also other family relationships were distorted or destroyed (Castellano, 2002). One serious consequence was the loss of traditional childrearing practices. Since these schools were not phased out until the last quarter of the $20^{\text {th }}$ century, persistent social problems including lack of parenting skills are still present today. Indeed, the Government of Canada recently gave financial compensation to residential school survivors, in part to recognize the cultural losses incurred by former students and Prime Minister Stephen Harper made an official apology on behalf of the federal government in June 2008. The child welfare "scoops" of children from reserves, sometimes removing all children in a community, was a horrific consequence of the residential school legacy. Within those circumstances, adult children, survivors of the residential schools, were brutally punished for the inevitable consequences of their upbringing. Carrying on the legacy from residential schools were child welfare scoops that penalized adult children of the residential school system for the very essence of what was stolen from them.

More recently, in the past two decades, newer policies and practices within First Nation communities have focused on strengthening families through revival of culture and language traditions via such community-based programs as Aboriginal Head-Start, Canadian Prenatal Nutrition, Fetal Alcohol Spectrum Disorder, and Maternal Child Health Programs. The effects of these programs on individual roles and responsibilities within the family, child development, community interrelationships, and strengthening parental competencies have yet to be established.

\section{Traditional roles of grandparents in Prairie First Nations Communities}

There have been some pockets of success in reviving traditional parenting practices and values, prior to the establishment of these programs. In Saskatchewan, for example, Aboriginal recollections of traditional grandparenting were shared in a study that emphasized grandmothers' stories (Ahenakew \& Wolfart, 1998). In this study, eight women were asked to remember their childhoods and to describe their childhood communities, in a series of non-directed interviews. The study results showed community spirit to be quite strong, and participants recalled moving from place to place with relatives. Fishing camps were established in the summer time, and trap lines were set in the winter. Whole families went fishing; various members of the communities, usually men, trapped while women prepared skins. Children interacted with different generations, and they learned language, spirituality, skills related to food gathering and preparation, and, in the case of girls, domestic skills such as sewing and beadwork.
In McDonnell's (2006) thesis work, grandparent participants were asked specifically to recall their grandparents, and similar results were found in Manitoba, as compared to Ahenekew and Wolfart's findings in Saskatchewan. When McDonnell (2006) asked her urban participants what activities they did with their own grandchildren, they reported teaching good patterns of food choices, "going to the mall," and discussing spiritual issues. Clearly many activities had changed in two generations.

\section{Focus of the Current Research}

The current study focused on relationships between children and their grandparents in Manitoba First Nation communities. In considering the details of this relationship, including strengths, health, social and economic needs of the individuals as well as of the family, and in light of evolving traditions, and the history of colonial policies towards Aboriginal Canadians and their implications, we chose to focus the study on the perceptions and life experiences of 10 Manitoba grandmothers. Through their stories, we show how past history, current family circumstances, grandparental health and familial responsibilities interact among participants. We begin with a description of the program from which we drew the data.

\section{The Manitoba First Nation Maternal Child Health Strengthening Families Program}

The Manitoba First Nation Maternal Child Health Strengthening Families Program (MFN-MCH-SF) is a federally funded program, jointly administrated, designed and implemented by the Assembly of Manitoba Chiefs and Health Canada, First Nation Inuit Health. The Manitoba First Nation Centre for Aboriginal Health Research, Department of Community Health Sciences, Faculty of Medicine, at the University of Manitoba is the research and evaluation partner that has established a strong and intimate relationship with the program and will follow the program from development into the long-term future. Currently there are 16 Manitoba First Nation communities that are funded to carry on the program (see Figure 1). The communities range in terms of geographic location, culture and language affiliations, population size, and infrastructure.

MFN-MCH-SF is an on-reserve, nurse facilitated home-visiting program offering support, advocacy and education to childbearing women, new moms, fathers and their families with children aged $0-6$ years. The community-based program teams work to support families, coordinate access to related health and social services (for example, access to services for children with disabilities), and provide health promotion and educational sessions linking with other community-based 


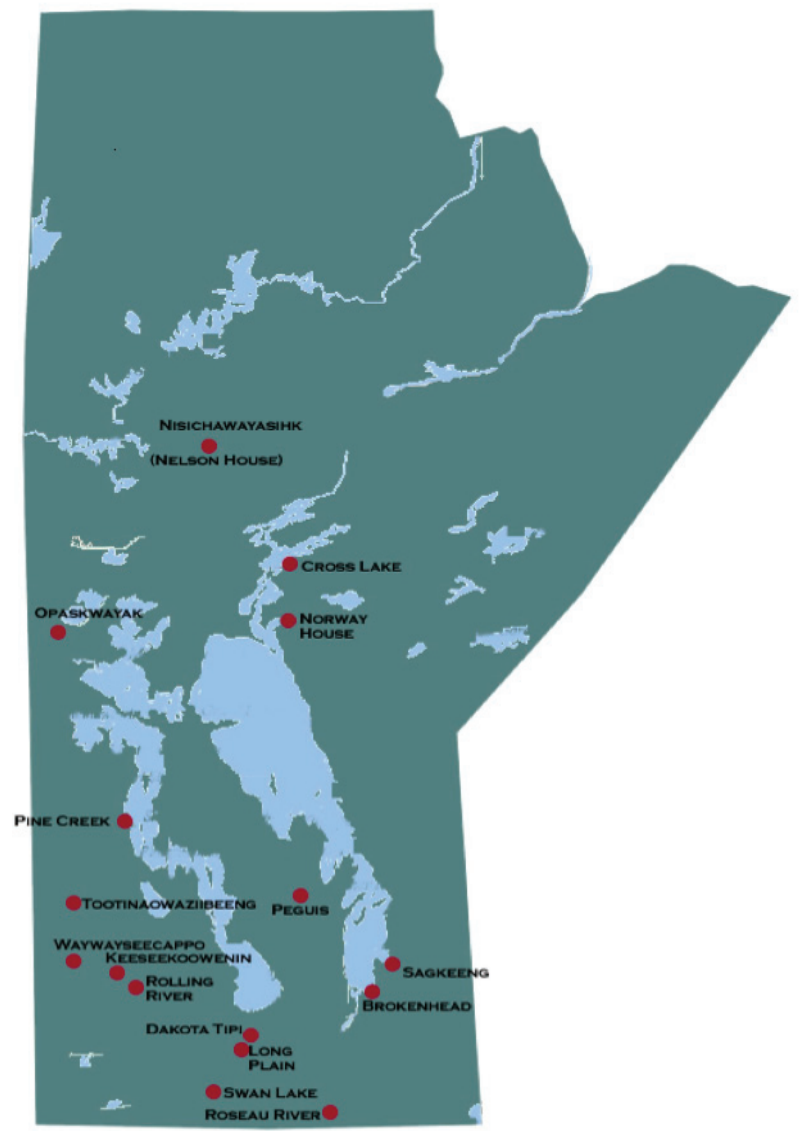

Figure 1. Manitoba First Nation SF-MCH Program Sites

programs. With an emphasis on enhancing the healthy development of children by supporting their mothers and extended families, our program considers issues pertaining to social justice, equity, and the contributions of community-based care giving to a population's overall health. As such, community program teams often meet regionally to explore topics related to their work with families and their own challenges as women, caregivers, professionals, family, and community members.

A comprehensive delivery approach has been made possible through partnerships with Elders, Canadian Prenatal Nutrition Program, Fetal Alcohol Spectrum Disorder Prevention Programs, and Aboriginal Head Start. Other partnerships formed or still being developed are with traditional midwifery programs, nursing services, home and community care, and oral health. At the provincial level, MFN-MCH-SF has established a strong relationship and collaborates with its provincial counterpart, Healthy Child Manitoba's Families First Program. The overall goal of the partnership program is to foster a network of support and strive toward a vision of program excellence to support all families, regardless of place of residence in Manitoba, thus attending to the massive jurisdictional problems within the system. It is hoped that a goal which is driven by the desire to offer the same level of services to on-reserve residents through this particular type of programming will work toward eliminating the health inequity that separates First Nation people from the rest of Canadians.

All research activities that flow from MFN-MCH-SF are implemented in such a way that it is the communities that define their direction and momentum. As researchers and programmers, our role is to develop community programming and policy interests from the community and then to regional and federal offices. Practices and policies are thus based on the life experiences of the people who will ultimately be affected by them. This is how the current research study came to be: We wondered what it was like to raise young children in Manitoba First Nation communities. To answer our questions, we turned to the experts, those doing the parenting.

\section{Study Methods}

Overall, the objective of the interviews was to understand parenting experiences for caregivers in the participating communities in order to inform better and relevant programming for families in the communities. A qualitative design was implemented in order to allow for an exploration that would situate the values and interests of the caregivers at the forefront. Our design allowed for more than "inclusion of Aboriginal presence, perspective and input into all aspects of self-determination" (de Leeuw \& Greenwood, 2003). Rather, our approach was an Aboriginal presented self-determination of maternal, child and family healthcare provision.

Community-based, exploratory, semi-structured, and open-ended interviews were conducted in twelve Manitoba First Nation communities. Sixty-seven parents (including 10 grandmothers as primary caregivers of biological, adopted and foster children as young as one month of age) participated in the study. Interviews were conducted by one or two First Nation research assistants in private family homes or at the community health centers, following participant preferences.

Ethical approval for the study was obtained from the University of Manitoba Health research Ethics Review Board and the Assembly of Manitoba Chiefs' Maternal Child Health Advisory Committee. Interviews were conducted from June to September 2007.

Participants were purposively selected by MFN$\mathrm{MCH}-\mathrm{SF}$ program coordinators in each community, using network sampling techniques. Interviews generally were 45-60 minutes in duration. All interviews were tape recorded with the consent of the participants 
and transcribed verbatim. Data were analyzed using interpretive descriptive methods and supported by NVivo Software.

\section{Description of the Participants and their Communities}

The grandmothers in this study lived in eight different First Nation communities throughout the province. The communities are small, ranging in size from 156 to 4,071 people. All of the communities are rural and semi-remote, located between 50 and 300 kilometers from a major urban centre (Winnipeg, Brandon, or Thompson). Most of the communities are connected to several neighbouring communities, represented by a single tribal council. For the purposes of programming, research and evaluation, all of the participating communities are represented by the MFN-MCH-SF Advisory Committee. Cultural and linguistic backgrounds of the participants are Cree, Ojibway and Dakota.

Although many of the reserve communities in Manitoba are remote and accessible only by air or winter highways, all of the participating communities had all-season road access. The bands are governed by tribal councils and monies for maintenance and programs come from the federal government. Major medical facilities are located in Winnipeg, the largest Manitoba metropolitan area, and at-risk patients are transported to Winnipeg for treatment.

Across Manitoba, social services and support programs are available in some First Nation communities but not in others. For the participating communities, there are MFN-MCH-SF programs, Canadian Prenatal Nutrition, Stop FASD, and Aboriginal Head Start Programs are available to families. High school is available in these particular communities up to Grade 12; therefore, high school students may live at home to finish school, a resource not available for smaller, remote reserves in Manitoba.

Poverty is an important and over-riding experience resident members of First Nation communities, as is the lack of suitable and adequate housing. Since many people are crowded into small homes, and since generations may live in close proximity, some families have children who live in one house but sleep in another. Access to housing and access to particular types of housing vary from one reserve to another.

Most of the grandmothers who participated in the study were in their $50 \mathrm{~s}(\mathrm{~N}=8)$, one was in her $40 \mathrm{~s}$, and another in her 60s. Four of them had dependent children of their own at home, as well as grandchildren living with them. Children varied in age from infancy to age 23; grandchildren were infants to age 7.

\section{Findings of the Study}

In this section we share the issues that the grandmothers found important in raising children in their communities. We learned a number of things that were spontaneously mentioned by the grandmothers. Here, we demonstrate the interrelationships among the issues, using theoretical ideas of Mr. Chartrand in his teachings of the Medicine Wheel to highlight how physical and social worlds intertwine and collide to create the everyday environments within which people raise their children.

\section{Cultural Transmission}

Within Anishinaabe and Ininew worldviews, depicted in our Medicine Wheel model, family health and overall wellness of individuals is understood as being interdependent upon the broader contexts within which family members live their lives (across time and space). Socioeconomic and political histories are fundamental to trends in First Nation family dynamics. Currently, Manitoba First Nations are implementing self-determination initiatives and are slowly transforming health and governance in their communities. Although many notable developments are taking place, much more needs to be done to ensure equitable overall wellness with the general Canadian population. In doing thus, Canadian governments and their institutions need to take a more active role in assisting First Nation in supporting implementation of their work.

Childrearing is a communal practice in many First Nations communities. Narratives collected by Ordolis (2007) showed that women are traditionally viewed as "keepers of the culture," and grandmothers particularly are to instill cultural values and identity. The grandmother participants expressed the value of keeping family members together. Indeed, many lived across the street from other relatives. They also wanted to stay in their reserve communities, rather than move to an urban area, despite the hardships in education, employment and social and recreational opportunities. Many expressed the belief that they were the caretakers of last resort, and they expressed the value of living for the children, sometimes not only their own but also for other community members as well. One said, "Oh, if these kids were in somewhere else, they'd probably be tossed from home to home."

Perpetuation of the culture is another function of grandmothers. Given the difficulties that some participants had in residential schools and the lack of interaction that they had with their communities when they were growing up, it is remarkable the value they expressed in re-learning traditional values and laws, and in participating in traditional activities. For some, First Nation culture was a lifestyle that was simultaneously being learned and taught to the younger generations. For 
example, one grandmother reclaiming aspects of her own culture, said of her grandsons, ages 9 and 10:

They have a real deep interest in the ceremonies. I go to a sun dance ceremony in Alberta. I've been dancing for-this is the $14^{\text {th }}$ year I've danced. And those little boys now know a lot about the sun dance.

This grandmother went on to explain that her grandson took such interest in the sun dance that he later wrote a paper on it in school. Through his writing on the sun dance, the grandmother learned his perspectives of culture and cultural revival.

Another grandmother described the pride she took in her developing new identity, she said:

The reason I wear a dress is I'm also a pipe carrier. And when you have a sacred pipe, you dress accordingly as a woman; you don't, you know, wear inappropriate clothes.

For a generation who had lived through the assimilation and exclusionist policies of the residential school system, it was a feat for them to be able to reclaim all that was lost and to work towards bringing back the teachings to their grandchildren. Through their stories, we learned the pain they held in their hearts of not being able to provide such gifts to their own children, and at the same time, the reward of being given "a second chance." This is a theme that recurred often in the stories of the grandmothers. McDonnell (2006) also discovered this theme in her research writing that the grandparents enjoyed the opportunity to interact with grandchildren when they felt that they had "failed" their own children. In our study, one grandmother told us:

I was telling my sister last night. I said, 'Isn't it neat about grandchildren? We have a chance after.'

On the other hand, this same grandmother said, "And we shouldn't be raising our grandchildren. I know this is happening a lot." We think that what she meant about this was that the parents should be more involved, rather than to say that the grandparents should be less involved. Grandparenting is a gift, but at the same time, some of the women lament the lack of active participation of their children.

\section{Safety}

Safety was a theme repeatedly expressed by the grandmothers. All of the study participants talked about the dangers of community living and the compensations they had to make in order to keep their children safe. Structural aspects of the communities caused a great deal of concern for caregivers. Lack of sidewalks or playgrounds, reckless or impeded drivers, proximity to highways, lack of road signs were of concern. Aggression from others, bullying, vandalism, and the "meanness of teenagers having not much else to do" were also concerns. Some of the comments regarding safety issue in the communities and the compensations made included the following:

\author{
We really don't encourage the kids to be going \\ anywhere. You know, we prefer they stay closer to \\ home.
}

The older kids are into drugs and stuff like that. So we need to keep an eye on that.

People go pretty darn fast down these roads.

I think they've been exposed to a lot of violencenot in my home but in their parent's home and the Mom and boyfriend's home. There might have been drugs and alcohol in both homes.

Many of the stories indicated the strong protective factor provided to the children by having access to their grandparents. By having grandchildren in their own homes, grandmothers can monitor the situations surrounding them and thereby protect them.

\section{Living with Granny}

The grandmothers offered information about the expressed thoughts of their grandchildren. Grandchildren enjoyed the time they spent with their grandparents for a variety of reasons. Mostly, the grandparental home offered a security to the children not accessible elsewhere. It established a sort of grounding for the children in terms of education, social values, emotional development, and care provision - a trustworthy and dependable source of acceptance. Some of the comments made that helped us to understand the importance of this relationship included the following:

\section{My granddaughter doesn't want to go home. She says she gets bad dreams about there. \\ My grandson could drop in and stay overnight or he can come back and go visit his mom. I say, 'visit' his mom because he spends the majority of the time at my house. \\ Sometimes the kids just say, 'grandma come pick us up, 'so I go pick them up.}

The examples illustrated the fluidity of the relationships and residences with the grandparents, indicating the active role of the extended family in child socialization, as Castellano describes is common among First Nation families (2002).

\section{House and Home}

The grandparents expressed concerns about the suitability of their houses and homes for raising children. Housing inadequacies such as overcrowding, lack of running water and modern toileting facilities in Manitoba First Nation communities are well known. It is important 
to understand however that despite their concerns, the participants expressed personal meanings and connections to their homes and life on the reserves. People were connected to their home communities through history, land and resource connections, personal relations, the calmness and predictability that the reserve offered. The reserve offers a kind of belongingness and acceptance as family, community, and First Nation people that was not accessible in the cities. At times, participants resided in particular First Nation communities that were not their own, because of marriage or other family relationship or responsibility discussed situations of exclusion from the membership. But overall, even these respondents preferred the community to living in the city.

The physical qualities of housing and the socioeconomic environment may have a negative impact on nurturing family relationships, however. The First Nation Regional Health Survey (RHS, 2002-2003) results indicated that on average, $61 \%$ of people living in First Nation communities live in band owned homes (58\% in non-isolated communities and $74 \%$ in isolated communities). A majority of people (52\%) living in these communities had not completed high school (48\% and $66 \%$ living in non-isolated and isolated communities respectively). More than half (i.e., 57\%) of the First Nations community population aged 15 years plus reported having an income in 2002.

According to a Canadian Mortgage and Housing Corporation report based on the results of the 1991 Aboriginal Peoples Survey, half of on-reserve Aboriginal households did not meet "adequacy standards" (full bathroom facilities and no need of major repairs). About one-third did not meet "suitability standards" (enough bedrooms for the household composition) and, among those renting or owning their homes about one-seventh $(14 \%)$ did not meet the affordability standard. These figures show significant discrepancy in comparison to non-Aboriginal Canadians.

Crowding is more common in First Nation communities and among people with less education, low socioeconomic status and those living in houses requiring major repairs. Overall 17\% of First Nations adults reported living in crowded homes. While occupant density has slowly decreased in Canada, the density in First Nations communities appears to have increased in the last 10 years. Many First Nation communities are building houses, but there is much more to be done.

Mold in houses is a problem in many First Nations' homes. In Manitoba some people will wrap plastic on the exterior of their homes to keep the house warm, and the result is the interior is damp, a condition which produces organisms which contribute to poor air quality and cause serious health problems, particularly asthma.
Household services and amenities often taken for granted in Canadian urban centers are inadequate or missing on reserves (RHS, 2002-2003). In First Nation communities, one in thirty lack cold and/or hot running water and flush toilettes. First Nations people were 17 times more likely to be lacking flush toilettes than Canadians in 1997. Overall, approximately one in seven First Nation people had neither a septic tank or sewage disposal available to them in their communities. In addition, a majority of homes on-reserve were found to be lacking fire safety equipment including smoke detectors, carbon monoxide detectors, and fire extinguishers (RHS, 2002-2003). The "per capita fire incidence rate is 2.4 times the . . rate for the rest of Canada," while the fire death rate is " 10.4 times greater; the fire injury rate is 2.5 times greater; and the fire damage per units is 2.1 times greater" (CMHC, 2007, p. 1).

Investigation of the main sources of safe drinking water showed piped water was accessible in $63 \%$ of First Nations communities, as compared to $99.8 \%$ of Canadians overall (RHS, 2002-2003). Trucked and well water was common to First Nations, and one in thirty households personally collected their water from rivers, lakes or ponds, the local water plant or a neighbor's home. Approximately 33\% of First Nations people consider their main water supply to be unsafe to drink.

Comments about inadequate, crowded housing were interspersed through all our interviews. The condition and safety of the houses is a problem for most of the participants. Overcrowding often results in generations living together, in homes that may have been flooded or are moldy.

I'd like to get my house painted and fixed upfor the kids because this place is very poorly structured. They were supposed to fix it and they didn't. That's what I mean: Sometimes it's okay and sometimes you don't get nothing done around here. Yeah, it's hard. The flooring is old and I had to buy them all morning slippers, thick pajamas, eh?

It's hard to live at my house because it has to be fixed up. The floor needs to be fixed; the bathroom needs to be fixed because we can't take showers there; the plumbing needs to be fixed there and the floor. I started saving up my money to do that, because I talked to housing a lot and they said they don't have no funding to fix houses and stuff.

\section{School}

A majority of people (52\%) living in Manitoba First Nation communities have not completed high school (47.8\% and $65.6 \%$ living in non-isolated and isolated communities respectively) (RHS, 2002-2003). Availability and accessibility of education and supporting resources 
are limited in the communities. The grandmothers in our study experienced great difficulties finding educational supports, particularly those for grandchildren with disabilities. Being able to feel confidence that there are others in the community upon whom the grandmothers could rely to assist them in adequately caring for their grandchildren was a problem that many struggled with, "if it isn't me looking after them, there's no one I can trust." One of the grandmothers shared the following:

They don't even know how to handle him in school. They're not taking up training ... And they grab him from behind in school and they're not supposed to. And I told them and told them.

I have a problem with the school system here ... A few of my grandchildren have been expelled. And they're just, like, 6 years old, 7, 8, and 9... Not listening and not paying attention ... I think they're a little harsh in their treatment of our children here in the community school.

\section{A Social Network of Kin}

According to the RHS (2002-2003), 66\% of children living in First Nation families lived in households with five or more people, mostly family members. The majority (83\%) lived with two adults or more; one-third lived with three or more children/youth. The number of household members ranged from 2-22 with a mean of 5.5. Adults living in the household ranged from one to eleven with a mean of 2.3. Almost all children living in First Nation communities (95\%) lived with one or more parents (biological, adoptive and/or step). Statistics Canada (2008) states that $65 \%$ of Aboriginal children living on-reserve resided with two parents and $33 \%$ resided with a lone parent. In comparison, $75 \%$ of Canadian families with children under age 15 in 2002 lived with two parents.

Other adults living in First Nation households included parental partners (i.e., boyfriends or girlfriends) and extended family members. About half of the households with parents and other adults included grandparents (or $16.5 \%$ of all households) and about half included aunts, uncles or cousins (or $15.5 \%$ of all households). In comparison, $2 \%$ of Canadian families were multigenerational in 2001 (RHS, 2002-2003).

The bulk of government housing (including band-owned homes) for First Nations people has been developed for the nuclear family in mind. Housing policies often ignore the reality of three or more generations residing in a single dwelling.

The RHS (2002-2003) Child Survey reported that alternate caregivers of First Nations children were most often relatives (59\%), enabling children to stay at home or in the community. This is quite different from other Canadians, whose alternate caregivers are not as likely to be relatives $(50.2 \%)$. We learned from our participants that the value and central significance of the children is one that people strive to uphold. People work together to try and keep the children in the community - but sometimes, because of social-psychological health or economic circumstances, are unable to do so. The loss of children to the state (i.e., Child and Family Services) is a tragic outcome with effects that ripple throughout families in the community and over generations.

Although formal assistance or respite care might be difficult to obtain, grandmothers did obtain informal support from other relatives when required. The grandmothers in this study described the help they obtained with in-home child care. One said her ex-partner, the grandfather, watched the children when she was at work, saying, "He lives right across the road." Adult children of the grandmother, sometimes co-resident, also provided assistance.

Oftentimes the grandmothers felt the strains of balancing work and family responsibilities as the care they received was not actually a 'substitute for the kind of care they were able to provide. One grandmother who worked full time and had an evening job as well explained this struggle as follows:
It was the next oldest teenage child helping with- to baby-sit while I was at work. I'd come back lunch hour, you know, quit at 4:30 and have to be back at work at 5:00.
My daughter comes and takes my two youngest
ones and the teenager at times too, for respite care.
At times, even other grandchildren themselves are expected to pitch in:
I tell them Granny's old and I have a hard time cleaning Granny's house and he's gotta help Granny. He helps his Granny when he picks up his toys and keep their toys in their room.

\section{Presence (and Absence) of Community Support}

Community support was available in some communities, and one participant was proud to say she took full advantage of the opportunities, saying, "Whenever they want participants, I'm willing to participate in anything." She had attended cooking classes, programs by Maternal Health, workshops by Child and Family Services, and anger management courses. She said, "I just let everybody know that I need a ride and they're pretty good with it."

Although activity around the development and implementation of social service programs in First Nation communities is expanding, several short comings remain and availability to such services is sometimes lacking. Several shortcomings remain and availability to such 
services is sometimes lacking. One grandmother was asked if she thought the community was helpful in the programs offered. She said:

\begin{abstract}
The worker that's supposed to be working with him visited us twice. She's not here now, though. . Nobody does their job right in this community.
\end{abstract}

In fairness to the workers, reasons for their inaccessibility might come from situations that are beyond individual control. In our programming and research activities overall, we found that workers in First Nation communities often suffer from professional isolation, burnout (from long hours and multiple demands), low wages, lack of access to appropriate training and other supports. Some workers told us that in order to do their jobs they often had to utilize their own resources.

Another grandmother said:

Well, I think their intentions are well-meaning.

But, again, that's where the catch is: Who's

delivering them? Yeah, who's delivering

them-consistency?

Daycare was considered a problem by some grandmothers. One woman lamented inconsistency in childcare, saying, "I put him in daycare. And then, they closed the baby lab down. So every day, I was struggling for a sitter."

Summers also could be a problem with a lack of things for children to do. Although swimming was available on at least one reserve, safety was still considered an issue due to lack of life guard supervision. As a result, most of the time, like one respondent's granddaughter, children are "just staying home watching TV, eating."

One grandmother said the only support she received is from her friends. Later in the interview she said she received help from her parents as well (the greatgrandparents), who are themselves foster parents, and from a local nurse practitioner, who the respondent said was "really supportive."

\section{The Need to Make a Living}

Access to employment was a problem mentioned by these grandmothers. One said she works mornings, because afternoon workers were required to make deliveries, so she told her supervisor, "Oh, I can't do deliveries. I don't got no vehicle." She went on to say she did not make much money, because babysitting costs take $5 / 6$ of her earnings.

More than half (i.e., 57\%) of the First Nation community population aged 15 years plus reported having an income in 2002 (RHS, 2002-2003), but the income they earned was low on average, about $8 \%$ lower than other Canadians. In 2001 the First Nation Regional Health Survey reported a median personal income in First
Nations communities of $\$ 15,667.00$ per annum. Income earning is correlated with education. More women than men worked part time.

Often, in order to be able to stay at home and take care of grandchildren, grandmothers sacrifice careers and income security. This might mean an end to personal opportunities and dreams of engaging in public activities that foster self-governance and other First Nation community development work that is of great meaning to the women. More practically, sacrificing employment may mean reducing access to the very resources required for healthy child development.

Opportunities for training and education on-reserve are limited and this poses restrictions on the type of work that people living in the communities can be qualified to do:

It's kinda difficult to get a job ... You need your certificate.

Gaining specialized training is usually offered offreserve, and grandmothers are needed for childcare at home.

\section{Health of Grandmothers and their Grandchildren}

The grandmothers spoke of health issues directly. They are concerned about their continuing ability to care for their grandchildren. One told us that she has asthma and noted, "The majority of our homes here in the community are still mold-infested." Another woman explained that she has lupus. Grandchildren's health was also discussed. One grandson has autism, coupled with a slight hearing loss. Some of the children have behavioral issues that required additional support and understanding of formal caregivers and educators. Treatment for children with more serious diseases and other special needs are generally located in Winnipeg and travel to the urban communities is difficult, expensive and often daunting for women who have the sole responsibility for more than one child.

The health of First Nation people across the lifespan, particularly in childhood and at older ages, affects the relationships between grandparents and their grandchildren. The age structure of Manitoba First Nations indicates a large number of young people, and few people in the oldest age brackets. This means that the burden of responsibility for care giving of the youngest (and largest) age group rests on the shoulders of the fewest people. Additionally, the oldest age group may also need care themselves, in terms of access to health/social services and economic security.

In 2000, life expectancy at birth for First Nations was estimated at 68.9 years for men and 76.6 years for women. These rates differ from the Canadian mainstream by 7.4 and 5.2 years respectively. Concurrently, the First Nation birth rate was 23.4 births per 1000 population, which is 
more than twice the Canadian rate. One in five First Nation births involved teenage moms. Cancer rates are increasing among First Nations; diabetes rates are known to be epidemic. There are severe impacts of diseases, revealing the serious lack of access to health services (Martens et al., 2007). Circulatory disease is the most common cause of death for First Nation people 45 years and older. Mental health impacts of residential school and alienation from family and community that may have resulted from the child welfare scoops of the eras have also left their scars on many of the eldest in the communities.

The stories of the grandmothers reveal a need for reciprocity of care giving between the youngest and oldest generations. Often, the only people that the grandmothers could depend upon to share in the care giving were older children (sometimes as young as 5-9 years of age). As caregivers, these grandmothers require support so that they can adequately take care of their own needs. Such support needs include healthcare, social support and networking, economic security, recreational and respite opportunities. Grandparents are people who have much to give, but they also deserve to have adequate resources themselves.

The high cost of food, inaccessibility of nutritious selections, and diminishing availability of traditional, wild foods and berries were also of concern to the participants. Although community-based programs do assist in the provision of healthy foods (milk formulas and cereals) to infants and pregnant women (staple foods), such provisions are not always available to families with older children. Additionally, the programs may not readily offer the support to grandparents that are offered to parents. As programmers and researchers, these are issues to which we need to pay closer attention.

\section{Summary and Implications for Policy and Research}

In this study, we examined grandparenting in Manitoba First Nation communities through MFN$\mathrm{MCH}-\mathrm{SF}$. We have examined the social and economic circumstances within which grandparents strove to raise healthy children, including crowded and inadequate housing, low community and personal income levels, high rates of disease, low educational attainment, and employment opportunities. In terms of access to the land and resources, traditional staples were diminished with technological developments of the Canadian government and corporate agendas. In spite of these obstacles the grandmothers turned houses into homes, protecting children from unsafe situations posed by unsettled parents or community level vandalism/violence.

Cultural transmission was a value and gift of the grandmothers to their grandchildren. Even those who had lost their cultures and languages as a result of colonization were students alongside their younger cares. The cultural values of reciprocity, extended family connection, and lifelong learning were evident here.

Grandmothers reported their grandchildren felt safe and loved in their care. The grandmothers tried to help their grandchildren get through school, even though their own educational attainment may have been low. They solicited help in childrearing when they needed it. They were actively involved in their communities, at times involving themselves in community services and at other times lamenting the lack of formal supports.

\section{Program Implications}

At present MFN-MCH-SF focuses on pregnant and new mothers. Since grandmothers are often involved with childcare, tangible supports to grandmothers ought to be available. Grandparents should be eligible for programs and services related to parenting, as well as having respite services and housework support. Some of our grandparents clearly needed respite and or assistance getting to medical appointments. Some had many people for whom they were responsible, and caring for one grandchild meant help was needed to care for others.

The grandmothers spoke about wanting to have recreational opportunities for their grandchildren, things that are accessible on foot and are safe for children. Expanded opportunities for children, youth, and respite care would alleviate some of the burdens carried by grandmothers. Employment opportunities for older teenage children are limited, and having something meaningful for teens to do would lessen grandmother worry about the young children in their care. Implementing strategies of such a nature will require partnerships beyond the maternal and child health programs and across jurisdictional boundaries and funding envelopes.

\section{Policy to Help Grandmothers Themselves}

Grandmothers we interviewed were in their 50s, still relatively young by Canadian standards. We wonder if they are sacrificing opportunities for their own development or satisfaction. Although they did not complain about needing things for themselves, perhaps some might seek additional training, education or different work if they had support with parenting responsibilities or were not the primary and sole supporters. Caregivers also require care themselves, especially since these individuals have already parented at least one generation. Health, social and recreational supports must be provided to these women.

Clearly grandmothers, like others on reserves, need better housing, sanitation, and water. They need homes that 
are big enough for the people who live there, as crowded conditions spread disease and affect overall wellness.

For health reasons, ridding homes of mold and creating a physical and nurturing environment that is adequate and safe needs to be a priority of the federal government.

\section{Culturally Appropriate and Flexible Family Policy}

These families are different from mainstream Canadian experiences, and the concept of "skipped generation" is inadequate. For the most part, First Nation grandmothers are younger than their Canadian counterparts, and their offspring may be very young parents (e.g., early teens). Therefore the flow between and among generations is continuous: Women become grandmothers while they are still raising children themselves. Grandchildren become part of the community, moving easily among various kin.

Since family life flows in a continuous stream from generation to generation, culturally appropriate and flexible policy is needed. Communities need to be supportive rather than punitive. Providing programming for parenting, for example, for grandmothers (and perhaps grandfathers, aunties, and uncles) can empower families across the life span. One of the advantages of having evaluation run parallel with program development is that the program has already responded to various identified needs. Opportunities and support for teens, young and older adults are required to assist these age groups in contributing more creatively and meaningfully to family and community life.

\section{Theoretical implications}

We began this study with an ecosystem or Medicine Wheel approach. We found this theoretical model useful to describe grandmothers' experiences, to organize their voices into themes, and to show interrelationships among various aspects of their lives. The approach is also useful to accurately present participants' lived experiences. This is a vantage point that is based on balance and harmony among distinct, explicit and interdependent roles and responsibilities of men and women.

Indigenism, as defined by Hart (2007) is the recognition that the influences of persistent colonization continue to affect Indigenous peoples. These influences are absorbed by the body and manifest health outcomes and affect even our intimate relationships. Rather than being a reaction to the dominant worldview, as are post-colonization theories, Indigenism is grounded in a distinction from a mainstream societal experience of the world. A discovery of the worldviews and practices that constitute Indigenism is, in itself, part of the learning process, as research participants actively engage in a research method that is self-determined, co-designed and delivered by Aboriginal health researchers, communitybased researchers, programmers, and family members (Eni \& Hart, 2008).

In choosing this particular methodology, researchers can support Indigenous voices within a specific space and time; enhance a meaningful relationship between researchers, health practitioners and program participants; reflect Indigenous core values and beliefs; recognize the role of researchers as subjective contributors to the generation and communication of knowledge; and remain practical to the everyday needs and desires of the study participants and their families (Eni \& Hart, 2008).

Emanating from a place that is outside of the mainstream discourse through inclusion of voices of different, non-European perspectives can gives researchers and participants in the research the power to direct a practical and academic work towards greater objectivity that escapes political bias and embraces the goal of social justice. As articulated by Tuhiwai-Smith:

[This is a methodology which] is expressed through
and across a wide range of psychological, social,
cultural and economic terrains. It necessarily
involves the processes of transformation, of
decolonization, of healing and of mobilization
as peoples. The processes, approaches and
methodologies - while dynamic and open to
different influences and possibilities - are critical
elements of a strategic research agenda (1999: 116).

Foucault referred to the silencing of other voices beyond the dominant white-male perspective as "subjugated knowledges" (1980a; 1980b). Including only a single voice into official government and academic discourses and relying on these as the basis for health and social policy and practice creates the illusion that what is written in the texts signifies all there is to know about the realities within which people live, breathe and feel. Researchers who omit the voices of the peoples living at the margins of society (as for example, in First Nation reserve communities located throughout provincial and national peripheries) create unbalanced, and in essence, false foundations for the development of policies, programs and services. The work of attending to the actual descriptions of everyday life by the people living in these communities, so far away from the Canadian centers, is a time consuming and difficult task. These data are not so readily available as are much of the quantitative and administrative data on Canadian populations; but the methodology offers a kind of analysis into real lives that is possible through no other means. It allows for a kind of research that has the potential for rebalancing our political system towards one that is socially just, equitable and humanitarian, and as such is a methodology that could be fully supported by the Canadian Aboriginal research agenda. With research that begins on side with the 
Aboriginal experience, researchers can express and share a multiplicity of perspectives and experiences and use these to reshape the patriarchal system so that is attentive to the needs, strengths and desires of the research participants, their communities and nations.

Within an Indigenous perspective, our goal is to discover a method of speaking as Indigenous peoples with a specifically defined set of values, traditions, ways of being in and interpreting the world, when in the end, political frameworks are created as per the paradigms of mainstream Canada. Embarking upon a community-initiated, community-lead and community-perspective research study that is meant to capture the essence of the modern-day grandparenting relationship, with implications to health and wellness, has revealed circumstances, value and belief systems that are qualitatively different from grandparenting relationships in the mainstream. In First Nation communities throughout Canada, many families and individual family members strive every day to free themselves from the legacy of colonialism and reclaim their cultures and traditions (for example, raising children within the context of loving, extended families) in spite of it all. Within the confines established by the Canadian governments and their institutions, First Nation peoples struggle to express an Indigenous way of being in the world - this poses a real challenge in doing practical First Nation health research. But within such a theory and method, we can represent the world from a particular socially situated perspective that can lay claim to epistemic privilege and authority.

\section{References}

Ahenakew, F. \& Wolfart, H. (Eds.) (1998). Our grandmothers' Lives. Regina: Canadian Plains Research Centre and the University of Regina.

Canadian Housing and Mortgage Corporation (CMHC)(2007). Fire prevention in Aboriginal Communities. Socio-economic Series 07-009/.

Castellano, M.B. (2002). Aboriginal family trends: Extended families, nuclear families, families of the heart. Ottawa: Vanier Institute of the Family. [Retrieved March 26, 2008 from http:// www.vifamily.ca/library/cft/aboriginal.html]

deLeeuw, S. \& Greenwood, M. (2003). Recognizing strength, building capacity: Addressing substance abuse related to special needs in First Nations communities of British Columbia's hinderlands. Substance Abuse Task Force: University of Northern British Columbia.

Eni, R. \& Rowe, G. (2009). Manitoba First Nation Perspectives on Youth Pregnancy and Parenthood Report. Unpublished Report INAC.

Fuller-Thompson, E. (2005). Canadian First Nations grandparents raising grandchildren: A portrait in resilience. International Journal of Aging and Human Development, 60, 331-342.
Goodman, C. C. (2007). Intergenerational triads in skipped-generation grandfamilies. International Journal of Aging and Human Development, 65, 231-258.

King, V. \& Elder, G. H. Jr. (1997). The legacy of grandparenting: Childhood experiences with grandparents and current involvement with grandchildren. Journal of Marriage and the Family, $59,848-859$.

Lawrenchuk, R. \& Harvey, C. D. H. (2001). Cultural adaptation and change: Aboriginal peoples in Manitoba maintain their differences. In C.D.H. Harvey (Ed.) Maintaining Our Differences: Minority Families in Multicultural Societies (pp. 71-88). Altershot, UK: Ashgate Publishing.

Martens P.J., Martin, B.D., O’Neil, J.D., \& MacKinnon, M. (2007). Diabetes and Adverse Outcomes in a First Nations Population: Associations with Healthcare Access, and Socioeconomic and Geographic Factors. Canadian Journal of Diabetes, 31(3): 223-232.

Martin-Matthews (2001). The Ties that Bind Aging Families. http:// www.vifamily.ca/library/cft/aging.html\#references.

McDonnell, D. P. (2006). Anishinabe grandparents: Perceptions of living with the effects of type 2 diabetes. Unpublished M.Sc. thesis, University of Manitoba.

Milan, A. \& Hamm, B. (2003). Across the generations: Grandparents and grandchildren, Canadian Social Trends, Winter, 2-7. Ottawa: Statistics Canada.

Monserud, M. M. (2008). Intergenerational relationships and affectual solidarity between grandparents and young adults. Journal of Marriage and Family, 70, 182-195.

Regional Health Survey (RHS) (2002-2003). RHS at a glance: Selected findings from the First Nations Regional Longitudinal Health Survey. Ottawa: First Nations Centre. [Retrieved March 31, 2008, from http:/rhs.ers.ca/English/pdf/rhs20023003reports/rhs at a glance.pdf].

Rosenthal, C. J. \& Gladstone, J. (2007). Grandparenthood in Canada. Ottawa: Vanier Institute of the Family. [Retrieved March 26, 2008 from http:www.vifamily.ca/library/cft/grandparenthood.html].

Rothausen-Vange, T.J. (2005). Family Diversity, a Sloan Work and Family Encyclopedia entry. [Retrieved March 30, 2007, from http://wfnetwork.bc.edu/encyclopedia entry. php?id=1138\&area=academics].

Standing, T. S., Musil, C. M. \& Warner, C. B. (2007). Grandmothers' transitions in caregiving to grandchildren. Western Journal of Nursing Research, 29, 613-631.

Statistics Canada (2008). Characteristics of the Population. [Retrieved April 8, 2008 from http://www12.statcan.ca/english/ census06/data].

Wang, Y. \& Marcotte, D. E. (2007). Golden years: The labor market effects of caring for grandchildren. Journal of Marriage and Family, 69, 1283-1296.

White, J. M. \& Klein, D. M. (2002). Family theories. Thousand Oaks, CA: Sage. 